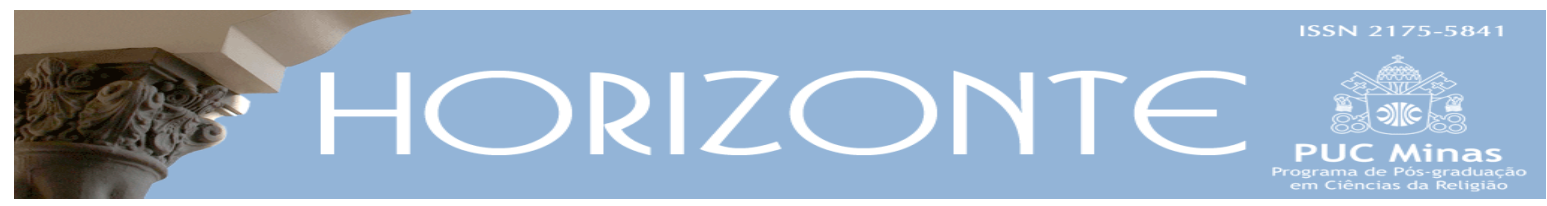

Dossiê: Narrativas Sagradas e Linguagens Religiosas - Artigo original (ㄱ) $(0)$

DOI - 10.5752/P.2175-5841.2016v14n42p240

\title{
Religião e linguagem: \\ proposta de articulação de um campo complexo
}

\author{
Religion and language: a proposal to articulate such a complex field
}

\begin{abstract}
Resumo
As relações entre religião e linguagem estão recebendo um novo tratamento nos programas de pósgraduação no Brasil por meio de grupos de trabalho de congressos, grupos de pesquisa e áreas de concentração dedicadas ao estudo do que se convencionou chamar de Linguagens da Religião. Esse artigo propõe uma articulação para essa nova área de estudos por meio de uma abordagem semiótica e cognitiva da temática, propondo o estudo da religião como sistema secundário de linguagem, por meio de três sistemas semióticos fundamentais: o gesto, a imagem (metáfora) e a narrativa. Esses encontram correlação na tríade: rito - ícone (poesia) - mito. Esses três sistemas se relacionam entre si criando textos híbridos e multicodificados na cultura, com alto poder de geração de novas mensagens. São tratados também os aspectos ficcionais e grotescos das expressões religiosas como alguns dos seus aspectos distintivos. Segundo os mesmos, apesar da religião estruturar o mundo como a linguagem, ela tende a fortalecer e explicitar os jogos de "como se" da cultura, além de levar as representações para os limites dos sistemas estabelecidos. Religião propõe, portanto, à cultura sistemas densos e caleidoscópicos de representação, por meio dos quais aspectos ambíguos e paradoxais da existência e da sociedade são articulados textualmente.
\end{abstract}

Palavras-chave: Linguagens da religião, semiótica da cultura, hibridismo, gesto, imagem, narrativa, ficcionalidade, grotesco.

\begin{abstract}
The relationship between religion and language is the focus of renewed attention in the Brazilian graduate programs in Religious Studies through Congress working groups and areas of concentration devoted to the study of what is conventionally called Religious Languages. This article proposes a link to this new field of study through a semiotic and cognitive approach, suggesting the study of religion as a secondary language system through three fundamental semiotic systems: gesture, image (metaphor) and narrative. Their religious counterparts are ritual, icon (poetry) and myth. These three systems work together as hybrid and multi codified cultural texts, with a high level of power in creating new messages. Finally, the article also discusses the fictional and grotesque aspects of religious expressions as well as some of its distinctive features. According to them, besides the fact that religion structures the world, religion tends to stress and explicit the "as if" games of culture, and pushes cultural representations to the borders of its established systems. Religion proposes to culture dense and kaleidoscopic representation systems, who articulate textually ambiguous and paradoxal aspects of social life.
\end{abstract}

Keywords: Religious languages, cultural semiotics, hybridism, gesture, image, narrative, fictionality, grotesque.

Artigo recebido em 16 de fevereiro de 2016 e aprovado em 21 de junho de 2016.

* Doutor em Theologie pela Universität Heidelberg (Ruprecht-Karls), Alemanha; Professor do PPG em Ciências da Religião da UMESP. País de origem: Brasil. E-mail: paulo.nogueira@metodista.br

Horizonte, Belo Horizonte, v. 14, n. 42, p. 240-261, abr./jun. 2016 - ISSN 2175-5841 


\section{Introdução}

As complexas relações entre linguagem e religião têm sido objeto de pesquisa e estudo na área das ciências da religião há muito tempo, mesmo quando não estão articuladas num campo de pesquisa específicos para isso. Quando se analisa as narrativas míticas, as tradições religiosas populares, ou formas específicas de construção social e religiosa da realidade, para mencionar apenas alguns tópicos clássicos, se aborda de forma direta ou indireta estruturas de linguagem. Nas diferentes hermenêuticas teológicas as questões também são colocadas em torno dessa problemática com rigor e precisão terminológica e conceitual. Ou seja, os estudos das relações entre linguagem e religião são antigos e se fazem representar nas pesquisas das ciências da religião e da teologia. O que haveria de novo, portanto, para que programas de ciências da religião no Brasil passem a se ocupar nos últimos anos mais enfaticamente da temática por meio de publicações, congressos, GTs, linhas de pesquisa e até mesmo áreas de concentração que busquem explicitar ainda mais a problemática ${ }^{1}{ }^{\mathrm{O}}$ que uma área de estudos das ciências da religião, intitulada Linguagens da Religião² (e variantes como Linguagens Religiosas ou Religião e Discurso, etc.) teria de novo a oferecer em termos teóricos e metodológicos frente ao fato de que tanto as ciências sociais, quanto a hermenêutica filosófica, teológica e bíblica já se ocuparem desse campo de estudos?

Nosso objetivo nesse artigo é apresentar o problema, proceder a delimitações iniciais e oferecer uma proposta de configuração teórica a esse campo de estudos, dentre várias possíveis, com a finalidade de promover a articulação de diferentes abordagens em torno da temática. Nossa reflexão deve ser considerada como estando aberta, em construção, nascida de contextos muito concretos e

\footnotetext{
${ }^{1}$ Para uma análise do papel da linha de pesquisa Linguagens da Religião na Pós-Graduação em Ciências da Religião da Metodista, por exemplo, ver o artigo de Etienne Alfred Higuet (2012), especialmente, p.353-365.

2 Usaremos nesse artigo a expressão "Linguagens da Religião", em maiúsculo, para nos referirmos a espaços institucionalizados de pesquisa, como áreas de concentração de programas de pós-graduação e "linguagens da religião" ao nos referirmos aos conjuntos expressivos das religiões, como os mitos, ritos, poesia, imagens, etc.
}

Horizonte, Belo Horizonte, v. 14, n. 42, p. 240-261, abr./jun. 2016 - ISSN 2175-5841 
práticos como oferecer pelas primeiras vezes um curso obrigatório de uma área intitulada Linguagens da Religião ou equivalente. Um curso inédito (ao menos nesse formato), em uma área de concentração recém-criada. É nesse contexto de work in progress, de busca por caminhos, que esse artigo deve ser lido e discutido. 3

\section{A configuração do campo de estudos Linguagens da Religião}

A constituição de um novo campo de estudos é sempre um processo delicado e, de certa forma, desconfortável. Decorre da consciência de que uma nova abordagem de um campo temático é necessária, mas que também se deve delimitar esse campo, justificar sua pertinência e refutar objeções de que há sobreposição desnecessária de interesses e perspectivas com outras áreas. Depois vem a tarefa da escolha e articulação das abordagens e referenciais a serem trabalhados na constituição de conceitos e teorias.

Comecemos com uma delimitação básica: o que uma área de estudos Linguagens da Religião não deveria ser. Linguagens da Religião se sobrepõe aqui e ali com temas e interesses comuns aos das áreas de estudos comunicação religiosa (tradicionalmente chamada de "comunicação cristã”) e estudos de mídia e religião. Por um lado, estudos de comunicação religiosa são frequentes em instituições religiosas que queiram formar seus quadros em habilidades que vão desde a comunicação no espaço do ensino e da liturgia até o uso de tecnologias para a divulgação da mensagem institucional. De cursos de teologia tradicional até centros de formação em uso de tecnologias para o trabalho missionário são as variantes de espaços institucionais que desenvolvem esse campo. Por outro lado, há muitos espaços acadêmicos que se ocupam de estudar criticamente as complexas relações entre instituições religiosas e os meios de comunicação. Há décadas as instituições religiosas deixaram de usar apenas púlpito e sala de aula para anunciar sua mensagem. De inserções radiofônicas e televisivas amadoras, em curtas entradas,

\footnotetext{
${ }^{3}$ Agradeço ao amigo Prof. Douglas Conceição (PPG-CR UEPA) pela leitura paciente desse artigo e pelas preciosas sugestões dadas.
} 
as diversas igrejas passaram não só a dominar profissionalmente essas técnicas de comunicação para se tornarem proprietárias de complexos de rádio e televisão. $\mathrm{O}$ domínio dessas técnicas e dessas mídias, além do uso da internet, não só projetou certos grupos religiosos na sociedade para patamares nunca antes imaginados, como também alterou sua relação com os crentes, muitos agora convertidos em telespectadores. A mensagem também se torna muito dinâmica nessas instituições, havendo interações curiosas entre mídia e mensagem, além de crises profundas com a tradição.

Pois bem, por mais pertinentes e necessárias que sejam essas abordagens, somos da opinião de que não é disso que trata a área Linguagens da Religião. O conceito que queremos abordar de linguagem difere do empregado nas perspectivas apresentadas acima. Ela é algo mais do que meio de comunicação de certos conteúdos e tem uma importância fundamental que antecede os processos e as estratégias de manipulação das novas mídias. Não sendo, portanto, nossa proposta centrada nos aspectos de comunicação religiosa (com ênfase em conteúdos) e nas relações de mídia e religião (com ênfase em aspectos técnicos e mercadológicos), de que se trata então?

Nossa proposta é a de estudar aspectos mais elementares, e também mais fundamentais, da relação entre religião e linguagem. A pergunta inicial poderia ser: como ambas se relacionam entre si? Uma primeira resposta seria que a linguagem estrutura a religião. Essa proposta, no entanto, pode sugerir que existe a linguagem como suporte e a religião como âmbito de conteúdo. No entanto, não é assim se que experimenta religião na realidade. Ao assistirmos uma missa católica ou a um ritual de umbanda, por exemplo, somos conduzidos por tempo e espaço, por meio de códigos estruturados, sendo que dessa forma temos uma percepção de evento de linguagem e de experiência religiosa de forma concomitante. Talvez possamos subir um nível em nossa determinação linguística da religião ao dizer que qualquer experiência religiosa só pode ser tornada social por meio das convenções linguísticas. Um visionário pode ter a experiência mais direta de Deus, mas ao 
torna-la pública, no compartilhamento com uma comunidade, ele tem que transformá-la em metáfora, em narrativa, etc., seguindo todas as normas e possibilidades criadas (e limitadas) pela linguagem. De fato, ao rememorarmos uma experiência vivida, o fazemos por meio de monólogos, e esses também são estruturados linguisticamente. Talvez no próprio imediatismo da experiência religiosa a linguagem também seja um elemento determinante, na medida em que na experiência classificamos, nomeamos, fazemos associações, etc. E não podemos nos esquecer que muitas nossas experiências religiosas são induzidas pela linguagem, por meio de hinos, orações, mantras, e na leitura de textos, etc.

Para delimitarmos melhor nossa busca pelas relações entre religião e linguagem, de modo que não repitamos a cada momento que uma não se reduz à outra, ainda que sejam interdependentes, optamos por um conceito de linguagem proveniente da semiótica da cultura de Iuri Lotman. Segundo o pensador russo, existem dois níveis de linguagem. O primeiro é o da língua natural, ou seja, os idiomas com os quais nos comunicamos no dia a dia e por meio dos quais estruturamos o mundo e nossa experiência quotidiana nele. Isso já era apontado por Vilém Flusser, segundo o qual, existe um mundo da língua portuguesa, da mesma forma que um mundo tupi, um mundo tcheco, um mundo chinês, e assim por diante (FLUSSER, 2007). As configurações dos idiomas, seu vocabulário e suas estruturas sintáticas moldam e determinam nossa experiência da realidade. Conforme o filósofo Wittgenstein: "os limites da minha linguagem são os limites do meu mundo" (WITTGENSTEIN, 1990, 69). Mas ainda não é esse nível de linguagem que queremos tratar de forma prioritária. Lotman entende que da mesma forma que existem as línguas naturais e seu poder de nomear o mundo, existem as linguagens de "segundo grau", as linguagens da cultura. Ou seja, as linguagens da cultura emulam as línguas naturais, constituindo-se em estruturas superiores de modelagem de mundo, o que Lotman chama de "sistemas modelizantes de segundo grau" (MACHADO, 2003, 125; LOTMAN, 2000, 168193). Nos dois níveis a língua não tem um papel de reproduzir o real, antes ela o molda, tornando-o possível. Retomando a analogia: da mesma forma que a 
língua fornece a uma criança, no aprendizado de sua língua materna, modelos para apreender o mundo em que vive, seus valores, etc., de forma similar a cultura, imitando a linguagem, nos dá modelos de mundo em suas linguagens específicas: a jurídica, a artística, a política, e a religiosa, entre outras. Nesse sistema lotmaniano, o dualismo entre linguagem (forma de expressão) e religião (conteúdos) se dissolve, uma vez que a própria religião se porta como um sistema secundário de linguagem, com poder de dar forma ao mundo. Por isso é necessário a qualquer pessoa que passe a frequentar um grupo religioso que ela seja submetida a um longo período de aprendizado de imagens, narrativas, gestos, classificações, hierarquias e árvores genealógicas de seres divinos e iluminados, de ações valorizadas e outras interditas, etc. Uma vez alfabetizado na linguagem de um grupo ele fala como tal, gesticula como tal, se insere nos complexos sistemas de organização da realidade desse grupo com confiança. A separação entre língua natural e linguagem da cultura, de segundo grau, tem valor heurístico: as pessoas religiosas não se dão conta disso, pois em suas práticas cultura e linguagem estão imbricadas uma na outra. O importante é que ao usarmos esse conceito podemos perceber a religião como um poderoso sistema de ordenamento do mundo.

Adotaremos também do conceito de linguagem de Lotman a sua concepção de cultura como um sistema híbrido de linguagem. Para Lotman não há exclusividade do sistema linguístico na cultura, como poderia ser acusada a semiótica de origem linguística. Lotman entende a cultura como a sobreposição e articulação de diferentes códigos em tensão: o fonético, o semântico, o rítmico, o gestual, o imagético, entre outros. Esses diferentes tipos de códigos em tensão favorecem a criação de novos textos, textos da cultura em constante transformação (LOTMAN, 1996, 83-90). Por isso nossa área de estudos Linguagens da Religião não se reduz ao estudo do código linguístico, incluindo diferentes processos semióticos em relação uns com os outros.

Esse conceito híbrido de linguagem nos permite estudar os textos religiosos em sua natureza complexa. Retomando os exemplos dados acima da missa católica 
e da sessão de umbanda, em ambas há uma sobreposição e interação de códigos semióticos em tensão, criando textualidades híbridas e da maior complexidade. Numa única missa ou sessão temos a palavra falada, cantada, os sons de instrumentos, os gestos, as imagens, a arquitetura, as sequências temporais de ações e falas. E o sujeito religioso, com todas as variações de seus códigos específicos, interage e cria novas textualidades. É por isso que a mesma liturgia é nova a cada performance. Se por acaso dois desses sistemas complexos se encontram numa forma mista de religiosidade, que contemple elementos de duas tradições diferentes e até aparentemente irreconciliáveis, teremos um aumento considerável na complexidade do novo ritual e a consequente produção de novas mensagens. Para a área Linguagens da Religião formas híbridas e sincréticas de religiosidade são de interesse prioritário.

\section{Os sistemas básicos das linguagens da religião}

Uma vez definida religião como um sistema secundário de linguagem da cultura gostaria de explicitar - na verdade apenas listar, dado o exíguo espaço - os eixos de trabalho no modelo que propomos na construção de uma área de estudos Linguagens da Religião. A escolha desses eixos é regida pelos sistemas básicos, elementares e fundamentais na cognição humana e na origem da linguagem, constituindo-se em pedras angulares da cultura. $\mathrm{O}$ assunto da origem da linguagem é muito espinhoso e possivelmente nunca encontre uma solução satisfatória (DESSALLES, 2009). O que possibilitou ao ser humano lançar mão de um recurso tão poderoso e contra intuitivo como a linguagem? Como essa habilidade ímpar surgiu, com que motivações? Quais as primeiras funções exercidas pela linguagem? E que tipo de linguagem surgiu primeiro no Homo Sapiens? São algumas das perguntas que se colocam os paleo-antropólogos, linguistas e psicólogos evolutivos. São também temas de interesse para as ciências da religião, uma vez que muitos dos pesquisadores da pré-história reconhecem a presença de manifestações 
religiosas nas origens das representações culturais humanas4. Sem nos preocuparmos com o que veio antes do que - por falta de competência para tanto, e por não ser necessário ao nosso argumento - podemos partir de três pedras angulares da constituição da linguagem e da cultura.

\section{a) $\mathbf{O}$ Gesto}

O mais antigo desses sistemas de linguagem é o gesto. Segundo Merlin Donald, o gesto aprendido mimeticamente é a forma de linguagem primordial e que deve ter antecedido por milhares de anos a origem da linguagem fonética (DONALD, 1991, 162-200). Trata-se de um sistema tão importante que as sociedades humanas nunca prescindiram dele. De fato, nós ainda o usamos o tempo todo. Esses gestos que estavam presentes nas origens seguem ainda vigentes nas sociedades em ações básicas e aprendidas por imitação como brincar, dançar, fazer gestos amistosos, reverentes, agressivos, no lascar pedras, caçar, gesticular para indicar comida ou predador, pedir, rejeitar, etc. O primado desse sistema gestual pode frustrar alguém que procure de cara a sofisticação dos sistemas linguísticos na origem da cultura e da religião. No entanto, os sistemas gestuais são tão poderosos e eficientes que nas celebrações religiosas estão presentes constantemente: nas formas de invocação, de exorcismo, de reverência, nas incorporações, possessões, etc. Eles não são aleatórios. Como na linguagem, se procede à escolha dos gestos apropriados e esses são inseridos em sequências corretas. Nas brincadeiras, por exemplo, há temas, enredos e narrativas. Ou seja, no sistema gestual existem, como na linguagem, os eixos paradigmático e sintagmático. Com isso queremos dizer que os gestos miméticos não são meras cópias gestuais da realidade, mas que se constituem num sistema de representações complexo e articulado. Os gestos são tão fundamentais quanto relativamente inexplorados na pesquisa. Vilém Flusser aponta para o fato de que

${ }^{4}$ Para uma discussão sobre a relação entre religião e arte na pré-história e seu papel na origem da linguagem, da cultura e da evolução cognitiva do ser humano ver Nogueira (2013). 
falta uma teoria geral dos gestos (FLUSSER, 2014, 13-29), ainda que existam explorações fascinantes do mundo dos jogos5. É no gesto que encontramos uma das ligações básicas da linguagem com o corpo. Não se pode prescindir do corpo nas Linguagens da Religião.

\section{b) Imagem}

O segundo sistema é o da imagem. A arte rupestre é uma de suas grandes manifestações na pré-história. No entanto não devemos imaginar que ela se limitasse à arte nas cavernas. A produção de objetos de culto e de apreciação estética portáteis acompanharam as sociedades pré-históricas e marcaram o início da inventividade e da cultura no Homo Sapiens. De fato, as imagens têm um papel fundamental nos sistemas semióticos. A acusação de que a virada linguística é logocêntrica, é apenas parcialmente verdadeira. Se o signo em Saussure é dividido em significante e significado, sendo o significante uma "imagem acústica" e o significado uma representação mental, podemos entender que na própria base da constituição do signo linguístico está presente a imagem. Repetindo o famoso exemplo: ao ouvir a palavra “árvore”, imagino uma árvore, ou seja, uma imagem de uma árvore em minha mente (SAUSSURE, 1995, 79-81). Na proposta de Lotman, invertendo o sistema de Saussure, o elemento central do signo é sua representação icônica, a imagem que evoca, relativizando assim a arbitrariedade do signo. Não se trata, no entanto, de reconhecer apenas que a representação mental e as imagens que invoca são centrais na linguagem. De fato, os sistemas semióticos visuais se constituem nos mais importantes e determinantes na cultura. Imagens não são representações cruas do real, elas constroem por meio de códigos visuais específicos (planos, gradações de luz, perspectiva, posições, cores, simetria, volume, etc) representações culturais do real (ROSE, 2007, 35-58). E ver uma imagem requer faculdades mentais e culturais sofisticadas: a principal delas é a imaginação (WULF, 2013, 23-25). Religião é de fato experimentada por meio de

${ }^{5}$ Sobre a importância dos gestos nas religiões remetemos ao texto de Wulf (2015).

Horizonte, Belo Horizonte, v. 14, n. 42, p. 240-261, abr./jun. 2016 - ISSN 2175-5841 
elaboradas práticas visuais (MORGAN, 2005, 55). Uma das conquistas recentes das ciências da religião no Brasil foi a descoberta dos estudos de cultura visual e da sua efetiva incorporação na área. A cultura visual e a semiótica da imagem devem ocupar cada vez mais um lugar central numa área Linguagens da Religião.

Ligada ao primado da imagem e dos sistemas visuais na cognição humana, está a metáfora. Ela é a imagem em ação nos sistemas linguísticos. Ao contrário do que se pensava há décadas atrás, metáforas não são apenas formas retóricas usadas para embelezar o discurso ou para tornar ideias mais acessíveis. Tampouco se pensa mais que metáforas sejam um tipo elementar de linguagem, enquanto que o pensamento abstrato e conceitual seja um tipo mais preciso e rigoroso de expressão. A pesquisa cognitiva desde os anos 80 tem proposto que todo o pensamento humano é essencialmente metafórico, seja nas estruturas metafóricas conceituais, derivadas do postural de nossos corpos, que funcionam como estruturas fundamentais da cognição, seja nas metáforas culturalmente limitadas, que igualmente moldam nossa forma de apreender o mundo (LAKOFF \& JOHNSON, 1980). Sem metáforas, sem dizer uma coisa por meio de outra, sem a projeção de âmbitos imagéticos, não há sequer pensamento filosófico ou científico. Mas não é com o pensamento abstrato que estamos preocupados aqui. Nossa ênfase na imagem e na metáfora se fundamenta no fato que elas se constituem em elementos fundamentais das linguagens da religião. Nesse aspecto a religião e a estética, para usar esses conceitos inapropriados para falar da origem da cultura, são poéticas, construtoras de mundos por meio de imagens transpostas. Não podemos nos esquecer também de observar que as metáforas são indispensáveis para as expressões narrativas e poéticas das religiões. Como as divindades, os ancestrais e os seres iluminados são entidades que pertencem a âmbitos distintos, o terreno, o subterrâneo e o celeste, ou como transpõem os limites do tempo, sendo do passado, de outras vidas, do futuro distante e interminável, ou abolindo o tempo, as comunidades religiosas só podem ousar se referir a eles por meio de 
metáforas. Essas projeções por sua vez, se associam a outras metáforas e âmbitos metafóricos criando labirintos poéticos fascinantes ${ }^{6}$.

\section{c) Narrativa}

Por fim, chegamos à terceira pedra angular da linguagem: a narrativa. A narrativa, da mesma forma que a metáfora, não é opcional, uma mera forma de informar ou ilustrar por meio de estórias ou de anedotas. Nas narrativas temos uma estrutura cognitiva fundamental que organiza ações eventualmente dispersas em um conjunto coeso de tempo, espaço, agentes e causalidade (TURNER, 1996; BOYD, 2009). Na organização de ações em tempo e espaço encontramos o que também pode ser chamado de cronotópos, tempo e espaço narrativos. A junção dessas duas categorias possibilita a construção do sujeito, de sua historicidade, de seu espaço de encontro com o outro (BAKHTIN, 2010, 211-362). Segundo Merlin Donald, a linguagem surgiu com o objetivo de narrar do mundo, e a forma por excelência dessa narração é o mito (DONALD, 1991, 258; ver também DEACON, 2009, 500). Aderindo a essa perspectiva também diríamos que essa forma elementar de narração, o mito, é a única que permite encaixar num texto elementos desconexos, improváveis, inesperados, aqueles mesmos com que os seres humanos se depararam ao se darem conta da grande assimetria, de que a cultura humana se constituía como uma das formas de enganar a morte, dando-lhe significado. Existe, no entanto, algo mais absurdo do que dar sentido à morte? É aqui que o mito entra em ação, como narrativa densa e improvável, e por isso indispensável.

Entendemos que é sobre esse tripé que está construída a linguagem e, mais especificamente, estão constituídas as linguagens da religião: sobre o gesto, sobre a imagem (e sua irmã, a metáfora) e sobre a narrativa. A cultura humana não pode prescindir de nenhuma delas, mas nem por isso se constituem em sistemas semióticos isolados. O que chamamos de mais elementar, o gesto, se constitui

${ }^{6}$ Sobre o poder de conectividade da metáfora, ver Danesi (2004). 
essencialmente de imagens, e essas imagens do corpo, no gesto, ganham sequenciamento espaço-temporal. Ou seja, gestos se constituem, de certa forma, em narrativas. Se a lógica do gesto é sequencial, o da imagem e da metáfora é associativa. Imagens e metáforas tendem a se organizar em campos imagéticos e metafóricos por meio de associações. Mas imagens também se associam com outras imagens fora de seus campos específicos criando caleidoscópios, como no universo onírico. Da mesma forma metáforas se unem às metáforas mais improváveis e assim constituem labirintos culturais que nos envolvem. No poder associativo das imagens e das metáforas da cultura e da religião há um potencial imenso para a criação de novos textos e complexos textuais. Por fim, a narrativa partilha do poder de associação da imagem, afinal narrativa é imagem em movimento, em várias cenas, tempo-espaço articulados, organizadas em torno de agentes. Mas ela também partilha da sequencialidade do gesto, de roteiros e enredos. No caso do mito ambas as características se potencializam: o mito é uma narrativa essencialmente imagética, que une os campos metafóricos mais improváveis para tratar dos grandes e improváveis temas, e lança essas conexões inusitadas para seus enredos. Ou seja, o mito é linguagem potencializada, usada para responder a questões difíceis, tornando-as de certa forma ainda mais complicadas. Trata-se de linguagem densa, aquela que consegue versar sobre coisas que não cabem.

\section{Hibridismo e amplificação}

Nossa analogia da linguagem com a religião propõe, portanto, as seguintes parcerias de sistemas semióticos elementares:

\begin{tabular}{|l|c|l|}
\hline Gesto & Imagem - Metáfora & Narrativa \\
\hline Rito & Ícone - Poesia & Mito \\
\hline Sequenciamento & Associação & Sequenciamento \\
\hline
\end{tabular}


Devemos observar, no entanto, que eles raramente se manifestam isoladamente, antes operam em cooperação (ou melhor, em tensão) uns com os outros, em textos híbridos. Uma liturgia religiosa raramente é puramente gestual. Ela tem de fato uma sequência organizada e significativa de gestos, acompanhada de estruturas narrativas, de imagens e metáforas. Pensemos na celebração eucarística: o celebrante abre os braços, estende as mãos, faz o sinal da cruz, eleva o pão, o partilha, eleva a taça, bebe da mesma, a oferece, se ajoelha, etc., de conformidade com o rito específico. Essas ações são regidas por certa sequência temporal, base da narrativa. E recorre à narrativa de fato ao ler as palavras evangélicas de dedicação do pão e do vinho. Todo o ritual é também perpassado por imagens e metáforas, desde a apresentação do paramento do sacerdote, da disposição do altar, do pão como símbolo do Cristo, até o pronunciamento da metáfora “eu sou o pão...”. Em outras celebrações religiosas esse sistema híbrido também entra em ação: a dança de um orixá frequentemente retoma elementos de seu mito, de suas ações ancestrais e de suas funções religiosas e culturais. Elas são acompanhadas por cantos que louvam a divindade e contam suas façanhas. Num nível mais profundo todos os três elementos - gesto, imagem, narrativa - estão implicados uns nos outros, pois são estruturas cognitivas e semióticas fundamentais. O gesto corresponde fundamentalmente ao elemento de referência do corpo humano no mapeamento do mundo. A cultura é uma grande brincadeira antropomórfica, de ficar dando características de ser humano ao cosmo. Não podemos nos desvencilhar de nossos parâmetros corporais, afinal, eles nos dão modelos, medidas e projeções para a sua compreensão. A imagem/metáfora é fundamental e está presente na constituição de qualquer representação ou mesmo de conceitos abstratos. Por outro lado, a sequencialidade narrativa e seus pressupostos de causalidade, de agenciamento, de mapeamento espaço-temporal referenciam todas as nossas hipóteses sobre o mundo, das mais elementares às mais complexas.

Devemos, no entanto, nos lembrar que não nos referimos a essa estrutura tripla da linguagem no seu nível quotidiano apenas, mas no nível secundário, no 
código da cultura e no da religião em particular. Ainda que essa divisão seja artificial e didática, e que de fato ambos os níveis partilhem das mesmas operações semióticas, as linguagens da religião têm sua especificidade em dois aspectos: primeiro, ao versarem sobre certos âmbitos complexos da vida social, segundo, pela intensidade com que o fazem. Religião se aplica às lacunas e o faz com textos amplificados. Ao versar sobre os temas que não encontrariam expressão na linguagem quotidiana, os textos religiosos precisam reinventar a inventividade da linguagem, amplificando-a. O jogo do “como se" da cultura, é tornado mais radical nas linguagens da religião.

\section{4 linguagens nas fronteiras}

As linguagens da religião se empenham em narrar e representar coisas díspares, impossíveis e excludentes. Elas tentam dar sentido a um mundo percebido como regido pela morte e pelo caos. Isso faz com que os textos religiosos pareçam de alguma maneira desajustados frente à linguagem funcional, quotidiana. Nas tarefas do dia a dia, ou nos âmbitos da técnica, a linguagem apropriada é a que comunica conteúdos com poucas chances de ser mal compreendida. Esperamos do piloto do avião no qual viajamos ou do dentista que nos atende uma perfeita compreensão de suas tarefas e dos procedimentos previstos nos manuais que estudaram. Já no âmbito das representações simbólicas, do que trata a religião em última instância, parece que tudo está em aberto, podendo ser lido e relido em diferentes perspectivas. Lotman nos adverte que a linguagem humana tende prioritariamente a produzir novos textos e não a repetir conteúdos emitidos. Por isso as linguagens monossêmicas são linguagens semioticamente pobres, pois uma vez compreendidas suas mensagens, cumpriram o seu papel. Mas os textos culturais não partilham dessa precisão dos manuais, pois, devido aos múltiplos códigos que os constituem, eles estão voltados para a produção infinita de textualidade (LOTMAN, 200ob, 11-19). Somam-se a essas variantes dos códigos dos textos os códigos dos receptores: isso amplifica ainda mais os processos de recriação. Esse é o equívoco dos fundamentalismos: atribuir 
aos textos religiosos a pobreza semiótica das linguagens monossêmicas, como se fossem manuais. Trata-se de um olhar essencialmente moderno sobre a poeticidade da religião.

Esse desajuste comunicacional das linguagens da religião, no entanto, não se restringe aos conteúdos. Religião se expressa por meio de formas que, principalmente na modernidade, são percebidas como oblíquas. Essa é uma dificuldade com que se depara o estudioso da religião quando quer entender como um grupo religioso expressa e interpreta sua realidade social. Ao estudar materiais sobre esse grupo ou ao visitar suas cerimônias o estudioso se defronta com um labirinto de entidades, de ancestrais, de narrativas de difícil compreensão, de poemas e cantos enigmáticos, de regras cuja origem ninguém sabe explicar, etc. Religião observada de perto ou lida em suas fontes difere sempre da organização e assepsia dos manuais. Principalmente nos cultos das periferias, devido ao dinamismo das construções simbólicas que ali são feitas, nada parece se encaixar à primeira vista, ainda que ao crente e ao devoto façam todo o sentido e emprestem sentido a um mundo de sofrimento e injustiças. Esse é um paradoxo fundamental para a área de estudo Linguagens da Religião: os grupos religiosos sempre escolhem os caminhos mais difíceis e tortuosos para falar das coisas mais urgentes e imediatas. Para falar da morte que os cerca (e que se manifesta de muitas formas na sociedade) eles se voltam para um passado mítico, por meio de narrativas que se contradizem, cuja origem ninguém conhece ao certo. Eles também prescrevem poções, rezas, invocações, evocam entidades de diversos universos culturais, muitas difíceis de definir a partir de critérios étnicos e de gênero. Essas observações nos aproximam de dois problemas centrais dessa área de estudos: os aspectos ficcionais e os elementos grotescos das linguagens da religião. Trata-se de característica de discursos de fronteira, à margem do estabelecido e das formas de expressão dos centros de poder. É verdade que os discursos religiosos são constantemente cooptados pelo poder político e pela sua ideologia. Mas nos parece, no entanto, que enfatizar apenas esse aspecto das linguagens da religião unilateralmente é desconsiderar seu poder de subversão, o qual é apenas 
superficialmente cooptado nos discursos oficiais. Onde há processos de recepção de textos religiosos, principalmente na cultura popular, nas margens e periferia dos sistemas dominantes, aí o potencial de inversão de mundo dessa linguagem tem chances de vir à tona.

\section{a) Ficcionalidade}

Toda linguagem socialmente partilhada fornece um modelo de mundo. Esse modelo de mundo é arbitrário, culturalmente delimitado. Ele apresenta o mundo como "ele é" sendo, no entanto, apenas uma forma de organiza-lo entre outras possíveis. Porém o jogo da ideologia do poder é precisamente dar transparência a essa linguagem, dando-lhe aura de realidade. Segunda essa perspectiva, o mundo é como o descrevemos e as relações sociais, étnicas, de gênero, etc. ali representadas são dadas como naturais. Cientes desse poder instaurador de realidade que a linguagem tem sobre o homem e a mulher comum, estados, partidos e grandes corporações investem muito dinheiro em repetir pedaços dessa realidade por meio de bordões, jingles, pequenas cenas padronizadas, comportamentos recorrentes, de forma que na nossa percepção imediata do mundo não tenhamos mais que pensar nas formas como ele é composto. Ele nos é dado.

Existem, no entanto, formas textuais que ousadamente tiram algumas pedras de apoio desse alicerce de realidade por meio de jogos ficcionais. Esse é o caso da arte, na qual os mais diferentes experimentos são feitos com a realidade. Shklovski, um dos expoentes do formalismo russo, chamava a atenção para o fato de que a complexidade de uma obra de arte tem como função nos tirar do automatismo da vida quotidiana, ao nos devolver o papel de sujeitos intérpretes, que precisam construir sua leitura/observação da obra. Nesse processo, a dificuldade que a obra impõe ao intérprete tem a função de fazer com que ele se detenha no processo da interpretação (TODOROV, 2008, 77-98). Na poesia, novas conexões metafóricas são testadas, enquanto que no teatro e na literatura papéis sociais e enredos são invertidos. Sobre esse papel de experimentação na literatura Lotman observa: 
"A cognição literária é uma cadeia de experimentos complexos. Um dos mais essenciais deles é esse: um fenômeno do mundo real aparece de forma inesperada em conexões-tabu, ou então numa perspectiva que revela aspectos ocultos de sua existência interior. A fantasia é o mais elementar exemplo desse rearranjo sistêmico" (LOTMAN, 1975, 202).

$\mathrm{Na}$ arte - e no caso do experimento ficcional literário - as arbitrariedades das construções de mundo sobre as quais repousam nossas práticas quotidianas são explicitadas e testadas em conexões inesperadas. No entanto, esse processo tem implicações ainda mais amplas do que o da experimentação estética. Segundo Wolfgang Iser, no romance o leitor, nos seus processos criativos e participativos de recepção, tem a chance de "horizontalizar" relações que na sociedade são dadas como verticais, portanto inegociáveis (ISER, 1975, 14-17). Entendemos que essas analogias com a fantasia e com a ficcionalidade literárias podem ser aplicadas na análise dos textos religiosos de fronteira, quando nas margens das sociedades e das culturas vigentes os sujeitos religiosos ousadamente criam novas formas de devoção e de relação com o sagrado (NOGUEIRA, 2015, 115-142). Para percebermos a importância desses experimentos religiosos temos que considerar a verdadeira dimensão que a religião ocupa entre as populações no mundo, com exceção de algumas poucas sociedades secularizadas europeias. Para elas religião é um sistema enciclopédico que versa sobre tudo, desde as coisas práticas, regulamentando-as, até vidas passadas e eventuais vidas após a morte, as coisas visíveis e as invisíveis. Tal vez por isso exista de fato uma dificuldade nas ciências da religião em definir o que é religião, pois ela é percebida como um todo, como uma lente que, de tão indispensável que é, as pessoas nem se dão conta de que existe. E se religião, vista como esse grande sistema cultural criador incessante de textualidades, ousar "horizontalizar" relações, todo um conjunto de saberes constituídos podem ser de fatos questionados. Esse potencial aumenta consideravelmente se os grupos religiosos estiverem nas margens da sociedade e dos seus poderes constituídos. 


\section{b) $\mathbf{O}$ grotesco}

As práticas de criação textual e imaginativas da religião não se limitam, no entanto, a apenas oferecer alternativas ao estabelecido que se apresenta como natural ou como legitimado. Ficcionalidade é uma característica que a religião compartilha com a arte, mas não é ainda seu elemento distintivo. As linguagens da religião se caracterizam, para além do elemento ficcional, por desafiarem não apenas os temas, mas as próprias formas da linguagem. Trata-se de um sistema de linguagem em choque com a linguagem. Nesse sentido a fronteira com que os textos religiosos lidam é uma fronteira dupla: a dos temas e hierarquias da sociedade e as do seu próprio sistema linguístico e cultural. Por isso uma das formas privilegiadas das linguagens da religião são as formas do grotesco.

O grotesco, apesar de estar profundamente relacionado com textos e imagens religiosas, não tem tido um tratamento adequado, e muito menos sido considerado um tema central, nas ciências da religião. Ele é comumente estudado na relação com as artes visuais e com a literatura. Mas podemos afirmar sem medo de errar que o âmbito cultural em que o grotesco mais de manifesta é o da religiosidade, em especial a religiosidade popular. Nos últimos anos surgiram os primeiros esforços de nossa área de estudar esse importante aspecto, aos quais desejamos nos aliar. A resistência ou mesmo a total desconsideração do grotesco na religião deve-se a pautas influenciadas pela modernidade e por certa compreensão de que religião deve se tornar relevante socialmente se cumprir certas pautas emancipatórias.

Uma definição do grotesco é impossível de ser dada, pois ele é constituído pela quebra de fronteiras, desrespeito às classificações, montagem de uma imagem a partir de partes não pertinentes7. O grotesco é tão amplo que pode ser relacionado à fertilidade da terra e à alegria vital do povo (carnaval), como também

\footnotetext{
7 Para uma discussão do conceito de grotesco remetemos às obras de referência: Bakhtin (1999); Edwards; Graulund (2013); Harpham (2006).
}

Horizonte, Belo Horizonte, v. 14, n. 42, p. 240-261, abr./jun. 2016 - ISSN 2175-5841 
pode estar associado às imagens do monstruoso e do abjeto. Ou seja, o grotesco é constituído pelas imagens que nos causam horror ou prazer desconcertante, ou os dois ao mesmo tempo. Ele nos desenha diante dos olhos a alteridade em formas que a amplificam. Suas formas estão presentes nas linguagens da religião desde manifestações sutis, como em narrativas estranhas e desajustadas, até milagres desconcertantes, martírios exagerados, relíquias de santos e seres encantados de funções ambíguas. O grotesco tem sua manifestação plena em seres monstruosos, descrições do além-mundo e do além-morte. Ele é tão presente, tão incorporado aos textos religiosos, que só o reconhecemos nas religiões do outro. Mas elas estão ali, do nosso lado, nos elementos centrais do cristianismo. Como exemplo, citamos a imagem do Cristo apresentado como um Cordeiro imolado exaltado em Apocalipse 5 ou o poder opressor como uma mulher/prostituta/cidade demoníaca e vampiresca (embriagada de sangue) em Apocalipse 17 e 18. Já convencionamos classificar a primeira imagem como cristologia e a segunda como "imagem de um império violento", num texto de "resistência contra o poder imperial”. No entanto, mesmo nos sendo mais fácil reconhecer o grotesco nas religiões que nos são mais estranhas, as imagens acima mencionadas não cabem nas classificações quotidianas. O grotesco pode, no entanto, nos servir para uma aproximação com as profundezas da psique humana, uma vez que elas partilham da liberdade imagética do inconsciente, mas também da cultura popular, que na exploração do corpo grotesco, de suas imagens e enredos, inverte o mundo e as relações por ele consideradas legítimas.

\section{Considerações finais}

Nesse artigo oferecemos uma visão de conjunto de conceitos e perspectivas que podem configurar uma base para a construção da área de pesquisa Linguagens da Religião em nossos programas de ciências da religião no Brasil. Trata-se de uma perspectiva entre outras possíveis e sua aplicação não é excludente, pois entendemos que pode ser articulada com outros saberes da área. A proposta que fizemos é cognitiva e semiótica e tem como pressuposto o fato que linguagem vai 
muito além de oferecer formas para expressão de conteúdos. Linguagem é um poderoso sistema de modelagem do mundo e de constituição de relações. Entendemos que as linguagens da religião (que configuram um campo com linguagens híbridas e densas) são um tipo de linguagem de segundo grau, linguagem da cultura. Como tal elas repousam sobre os três sistemas semióticos fundamentais: o gesto, a imagem/metáfora e a narrativa. Nas linguagens da religião suas contrapartidas são: o rito, o ícone/poesia e o mito. Elas se articulam entre si reforçando o hibridismo e a múltipla codificação dos textos religiosos. Isso dota as linguagens da religião de grande poder de geração de sentido.

As linguagens da religião compartilham do poder da linguagem na organização do mundo. No entanto, elas vão além dessa função e até a subvertem no exercício de duas características: a ficcionalidade e o grotesto. Na primeira, imagens de referência, temas e enredos são explorados e experimentados em conexões alternativas, permitindo aos sujeitos religiosos experimentar papéis inusitados e até não autorizados. Na segunda, a própria linguagem quotidiana e seu poder de referenciar o mundo é desconstruída: as formas e classificações elementares são desmontadas e recombinadas, formando imagens caleidoscópicas. $\mathrm{Na}$ ficcionalidade joga-se prioritariamente com a sequencialidade, no grotesco com as associações.

Essa proposta cognitiva e semiótica que apresentamos deve certamente ser complementada por outras abordagens que permitam estudar as linguagens da religião em ação na sociedade. Nosso próximo passo seria compensar o grau de abstração da abordagem semiótica com estudos discursivos, que privilegiem o dialogismo, o enunciado e a constituição dos sujeitos, por meio de conceitos de Bakhtin e da análise do discurso francesa. E na consideração do poder da metáfora e da narrativa religiosa e de seu impacto na cultura ocidental, por meio de suas imagens e enredos recorrentes, exploraríamos a metáfora total e os enredos do monomito na obra de Northrop Frye, em diálogo com o mitologismo de Eleazar Meletinsky. A relação da religião com a palavra poética, com o corpo e com a 
memória seria retomada e aprofundada na obra de Rubem Alves. Mas isso seria tema para outro ensaio.

\section{REFERÊNCIAS}

BAKHTIN, Mikhail. A cultura popular na Idade Média e no Renascimento. O contexto de François Rabelais. 4.ed. São Paulo/Brasília: Hucitec/Editora UnB, 1999.

BOYD, Brian. On the Origin of Stories. Evolution, Cognition and Fiction. Cambridge \& London: The Belknap Press of Harvard University Press, 2009.

DANESI, Marcel. Poetic Logic: The Role of Metaphor in Thought, Language and Culture. Madison: Atwood Publishing, 2004

DEACON, Terence W. The Symbolic Species. The Co-evolution of Language and the Brain. New York: Norton, 1997.

DEACON, Terrence W. ; CASHMAN, Tyrone. The Role of Symbolic Capacity in the Origins of Religion. Journal for the Study of Religion, Nature and Culture 3.4 (2009), p. 490-517.

EDWARDS, Justin D.; GRAULUND, Rune. The Grotesque: The New Critical Idiom. London: Routledge, 2013.

FLUSSER, Vilém. Gestos. São Paulo: AnnaBlume, 2014.

FLUSSER, Vilém. Língua e Realidade. São Paulo: AnnaBlume, 2007.

HARPHAM, Geoffrey Galt. On the Grotesque. Strategies of Contradiction in Art and Literature. Aurora/Colorado: The Davies Group, 2006

HIGUET, Etienne A. Reformulação do programa de pós-graduação em ciências da religião da Universidade Metodista de São Paulo: Aspectos históricos e epistemológicos. Numen: Revista de Estudos e Pesquisa de Religião, Juiz de Fora, v. 15, n.2, p. 343-375, 2012.

PASSOS, João D.; USARSKI, F. (Org.). Compêndio de Ciência da Religião. São Paulo: Paulinas;Paulus, 2013.

LAKOFF, George; JOHNSON, Mark. Conceptual Metaphor in Everyday Language. The Journal of Philosophy, Vol.77, n.8 (Aug. 1980), p. 453-486.

LOTMAN, Iuri. La semiosfera I: Semiótica de la cultura y del texto. Valencia: Frónesis, 1996.

Horizonte, Belo Horizonte, v. 14, n. 42, p. 240-261, abr./jun. 2016 - ISSN 2175-5841 
LOTMAN, Iuri. La semiosfera III. Semiótica das las artes y de la cultura. Valencia: Frónesis, 2000.

LOTMAN, Yuri M. Universe of the Mind. A Semiotic Theory of Culture. Bloomington: Indiana University Press, 200ob.

MACHADO, Irene. Escola de semiótica. A experiência Tártu -Moscou para o estudo da cultura. São Paulo: Fapesp/Ateliê, 2003.

NOGUEIRA, Paulo A. S. Linguagens Religiosas: Origem, estrutura e dinâmicas. In: PASSOS, João Décio; USARSKI, Frank Usarski (Orgs.). Compêndio de Ciência da Religião. São Paulo: Paulinas/Paulus, 2013, p. 443-455.

NOGUEIRA, Paulo A. S. Religião e ficcionalidade: modos de as linguagens religiosas versarem sobre o mundo. In: NOGUEIRA, Paulo A. S. Religião e Linguagem. Abordagens teóricas interdisciplinares. São Paulo: Paulus, 2015, p.115-142

NOGUEIRA, Paulo A. S. Religião e linguagem: Abordagens teóricas interdisciplinares. São Paulo: Paulus, 2015.

ROSE, Gillian. Visual Methodologies: An Introduction to the Interpretation of Visual Material. 2. ed. Los Angeles: Sage Publications, 2007.

SAUSSURE, Ferdinand de. Curso de linguística geral. São Paulo: Cultrix, 1995.

TODOROV, Tzvetan (compilador). Teoria de la literatura de los formalistas rusos. Buenos Aires: Siglo Veintiuno, 2008 ( $2^{\mathrm{a}}$ ed.)

TURNER, Mark. The Literary Mind. The Origins of Thought and Language. Oxford: Oxford University Press, 1996.

WITTGENSTEIN, Ludwig. Tractatus logico-philosophicus. Philosophische Untersuchungen. Leipzig: Reclam, 1990.

WULF, Christoph. Homo pictor: imaginação, ritual e aprendizado mimético no mundo globalizado. São Paulo: Hedra, 2013.

WULF, Christoph. O gesto na religião e na fé. In: NOGUEIRA, Paulo A. S. Religião e linguagem: Abordagens teóricas interdisciplinares. São Paulo: Paulus, 2015. p. 89-112. 